\title{
BMJ Open Long-term ambient air pollution exposure and self-reported morbidity in the Australian Longitudinal Study on Women's Health: a cross-sectional study
}

\author{
Nina Lazarevic, ${ }^{1}$ Annette J Dobson, ${ }^{1}$ Adrian G Barnett, ${ }^{2}$ Luke D Knibbs ${ }^{1}$
}

To cite: Lazarevic N, Dobson AJ, Barnett AG, et al. Long-term ambient air pollution exposure and selfreported morbidity in the Australian Longitudinal Study on Women's Health: a crosssectional study. BMJ Open 2015;5:e008714.

doi:10.1136/bmjopen-2015008714

- Prepublication history and additional material is available. To view please visit the journal (http://dx.doi.org/ 10.1136/bmjopen-2015008714).

Received 13 May 2015 Revised 8 September 2015 Accepted 24 September 2015

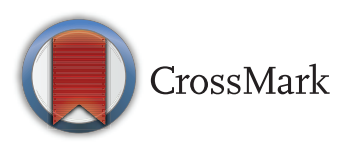

${ }^{1}$ School of Public Health, Faculty of Medicine and Biomedical Sciences, The University of Queensland, Brisbane, Queensland, Australia

${ }^{2}$ School of Public Health and Social Work, Faculty of Health, Queensland University of Technology, Brisbane, Queensland, Australia

Correspondence to Dr Luke D Knibbs; I.knibbs@uq.edu.au

\section{ABSTRACT}

Objective: We sought to assess the effect of longterm exposure to ambient air pollution on the prevalence of self-reported health outcomes in Australian women.

Design: Cross-sectional study.

Setting and participants: The geocoded residential addresses of 26991 women across 3 age cohorts in the Australian Longitudinal Study on Women's Health between 2006 and 2011 were linked to nitrogen dioxide $\left(\mathrm{NO}_{2}\right)$ exposure estimates from a land-use regression model. Annual average $\mathrm{NO}_{2}$ concentrations and residential proximity to roads were used as proxies of exposure to ambient air pollution.

Outcome measures: Self-reported disease presence for diabetes mellitus, heart disease, hypertension, stroke, asthma, chronic obstructive pulmonary disease and self-reported symptoms of allergies, breathing difficulties, chest pain and palpitations.

Methods: Disease prevalence was modelled by population-averaged Poisson regression models estimated by generalised estimating equations. Associations between symptoms and ambient air pollution were modelled by multilevel mixed logistic regression. Spatial clustering was accounted for at the postcode level.

Results: No associations were observed between any of the outcome and exposure variables considered at the $1 \%$ significance level after adjusting for known risk factors and confounders.

Conclusions: Long-term exposure to ambient air pollution was not associated with self-reported disease prevalence in Australian women. The observed results may have been due to exposure and outcome misclassification, lack of power to detect weak associations or an actual absence of associations with self-reported outcomes at the relatively low annual average air pollution exposure levels across Australia.

\section{INTRODUCTION}

Ambient air pollution is one of the leading environmental risk factors in the global burden of disease. ${ }^{1}$ Current evidence suggests adverse effects of air pollution on

\section{Strengths and limitations of this study}

- This is the first Australian national-scale air pollution study examining the effects of long-term ambient air pollution exposure on chronic morbidity in women.

- Individual-level data on numerous self-reported medical conditions and confounding variables were linked to exposure estimates at residential addresses using a validated national land-use regression model.

- An inherently low signal-to-noise ratio with uncertainty in both outcome and exposure measurement may have biased the results towards the null.

cardiovascular, respiratory, metabolic and allergic diseases, with outdoor particulate matter (PM) air pollution responsible for approximately $3 \%$ of global cardiorespiratory mortality. $^{2}$

Although air pollution levels in Australia are considered low in comparison to other economically developed nations, ${ }^{3}$ the Australian population is concentrated in major cities where air pollution exposure is ubiquitous and more likely to be elevated due to proximity with emissions sources. Given the large proportion of the population exposed to air pollution, even small estimated effects would increase the risks of air pollution-associated morbidity and mortality in Australia.

Recent systematic reviews and metaanalyses suggest modest positive associations between ambient air pollution and cardiorespiratory and metabolic diseases. ${ }^{4-7}$ Short-term air pollution effects have been extensively studied, especially in relation to cardiorespiratory outcomes. Long-term effects of cumulative exposure at ambient levels are less understood despite concern that chronic exposure increases morbidity and mortality risk to a greater extent than 
short-term exposure. ${ }^{8}$ In the case of respiratory and allergic diseases, air pollution is known to result in acute exacerbations of existing conditions, but there is uncertainty in the role of air pollution in the development of adult-onset disease. ${ }^{9} 10$

Differential effects of air pollution exposure by gender have been recorded, with evidence of stronger associations in women. ${ }^{11-13}$ Differences in male and female lung architecture and the effects of hormonal status have been proposed as explanations ${ }^{14}$; however, few studies have limited their attention to women specifically. The aim of this study was to determine if there are associations between ambient air pollution and the prevalence of several chronic health conditions among Australian women. We thus sought to add to the limited evidence base on the specific effects of long-term exposure to ambient air pollution on women in a relatively low pollution setting.

\section{METHODS}

\section{Australian Longitudinal Study on Women's Health}

The Australian Longitudinal Study on Women's Health (ALSWH) is a population-based prospective longitudinal study that started in 1996 to assess factors that affect the health of Australian women. Participants were recruited randomly from the Medicare database (Australia's universal healthcare scheme), with deliberate overrepresentation of women living in non-urban areas to account for the marked concentration of the Australian population in coastal cities. ${ }^{15}$ Participants are surveyed by mail every 3 years to collect a self-reported assessment of their physical and emotional health, health-related behaviours, risk factors, and sociodemographic characteristics. The ALSWH is approved by the research ethics committees of the University of Queensland and the University of Newcastle. Further details of the study can be found online (http://www.alswh.org.au) and in Lee et al. ${ }^{15}$

The present study focuses on survey responses from 26991 participants collected in the fourth (2006) and fifth surveys (2009) of women born between 1973 and 1978 (the 'younger' cohort, aged 31-36 years at the later survey), the fifth (2007) and sixth (2010) surveys of women born between 1946 and 1951 (the 'middle-aged' cohort, aged 59-64 years at the later survey), and the fifth (2008) and sixth (2011) surveys of women born between 1921 and 1926 (the 'older' cohort, aged 85-90 years at the later survey). This time frame was selected to match the availability of exposure data. Only de-identified data were used for privacy reasons; address geocoding and exposure assignment were conducted separately to data analysis, with only alias postcodes available to the data analyst.

\section{Outcome measures}

The study examined the self-reported presence of six diseases with plausible links to air pollution: diabetes mellitus, heart disease (includes angina, heart attack, other heart-related problems), hypertension, stroke, asthma, chronic obstructive pulmonary disease (COPD; includes bronchitis and emphysema). We also examined self-reported symptoms of allergies (includes hay fever and sinusitis), breathing difficulties, chest pain, and palpitations. We used iron deficiency as a negative control ${ }^{16}$ as it is not believed to be associated with ambient air pollution, but is likely to be affected by the same unobserved confounders as the outcome-exposure relationships of interest.

Disease data were obtained from survey questions asking participants whether they had been diagnosed or treated for the medical condition in question in the previous 3 years. Responses were dichotomous. Symptom data were obtained from survey questions asking participants how often they had experienced a particular symptom in the previous 12 months. Responses were on a four-point ordinal scale: never, rarely, sometimes or often. The symptom frequency response variable was dichotomised to avoid the subjectivity associated with the given ordinal scale and reporting heterogeneity bias. $^{17} 18$

\section{Exposure data}

Ambient air pollution exposures were estimated using a national satellite-based land-use regression model, described in detail elsewhere. ${ }^{19}$ Briefly, it is capable of capturing $81 \%$ of spatial variability in annual mean ambient $\mathrm{NO}_{2}$ levels across Australia, with a prediction error of $19 \%$. We used $\mathrm{NO}_{2}$ as a proxy for ambient air pollution because it exhibits greater spatial heterogeneity than other ambient air pollutants, and is produced by major ambient pollution sources like motor vehicles and industrial processes. ${ }^{20}$ Exposure estimates were assigned to geocoded residential addresses, with longterm ambient air pollution exposure defined as the predicted annual mean $\mathrm{NO}_{2}$ concentration at the place of residence. We did not have access to comparable national-scale models for other pollutants.

We also assessed residential proximity to major and minor roads at the time of survey completion as a proxy for traffic-related ambient air pollution. Major and minor road definitions were based on the Public Sector Mapping Agencies Australia Limited road classification hierarchy. ${ }^{19}$ Where an address could not be matched exactly during geocoding, the next best match was attempted (eg, next door or same street), and if no matching street number or name could be located, matches were made to the postcode centroid. We assessed the sensitivity of our results to the accuracy of address geocoding.

For the disease prevalence analysis, a 3-year average annual $\mathrm{NO}_{2}$ exposure was assigned (over the year of the survey and 2 years prior) to correspond to the 3-year time period in the survey outcome questions. For the symptom prevalence analysis, the annual mean $\mathrm{NO}_{2}$ concentration in the year immediately prior to the survey year was assigned as the exposure. This was 
selected because surveys were conducted at the beginning of the calendar year and variability in annual mean $\mathrm{NO}_{2}$ is negligible in proximate years (correlation coefficients between the years of the study period were all greater than 0.99 ).

\section{Sample selection}

The disease questions were asked across all three age cohorts except in the case of stroke, which was asked only in surveys of middle-aged and older women. Only the second of the two surveys for each respondent (between 2009 and 2011) were used because exposure estimates were only available between 2006 and 2011, and exposures were required to correspond to the 3-year period referred to in the disease questions. The disease prevalence analysis was thus performed on pooled data from the fifth survey of the younger cohort, and the sixth surveys of the middle-aged and older cohorts (see online supplementary section 1 for further details), except for the stroke outcome for which data on the younger cohort were unavailable.

Responses from both surveys of respondents in each age cohort were included in the symptom analysis. Allergy and palpitation outcomes were only assessed in surveys of younger and middle-aged women; chest pain was assessed in surveys of middle-aged and older women; and breathing difficulty was assessed across all three cohorts, but not in survey 4 of younger women.

We restricted the sample to those respondents with no missing data on the variables used in the analysis to first exclude respondents with missing outcome, exposure and postcode data. We then restricted the disease prevalence analysis and models which accounted for clustering by postcode to movement below an arbitrarily chosen $5 \mathrm{~km}$ residential mobility threshold (see online supplementary table S1). We did this to avoid unduly excluding participants whose apparent movement over short distances between surveys was more likely due to differences in geocoding results rather than an actual change of residence (we did not have access to residential addresses for comparison). At the same time, we wanted to identify participants who had moved during the preceding 3-year period and were not suitable for the disease prevalence analyses. We assessed the sensitivity of our results to this choice of mobility threshold (see online supplementary section 2 for further details).
Response rates in the ALSWH for the younger cohort surveys were $71.1 \%$ for survey 4 and $61.4 \%$ for survey 5 ; in the middle-aged cohort, these were $86 \%$ for survey 5 and $83 \%$ for survey 6 ; in the older cohort these rates were $77.4 \%$ for survey 5 and $70 \%$ for survey 6 . Table 1 shows sample composition by survey and cohort, and online supplementary table S1 shows the derivation of analytical sample sizes with the number of missing observations by outcome.

\section{Covariates included as confounders}

Covariates included for confounding control included age group, body mass index (BMI), smoking status, alcohol intake, physical activity, fruit and vegetable consumption, degree of residential urbanisation or remoteness, annual mean temperature, marital status, educational attainment and self-assessed financial resources. The definitions used for these covariates are given in online supplementary section 3 . We selected these confounders on the basis that they may be associated with the outcomes of interest and with exposure. Online supplementary tables S2 and S3 show descriptive statistics by outcome and covariate for the disease and symptom data, respectively.

\section{Statistical analysis \\ Spatial autocorrelation}

To partially account for the spatial autocorrelation observed in the exposure data, respondents were assumed to be clustered within postcodes. Alias postcodes were used for privacy reasons, which have a one-to-one mapping with actual postcodes. Latitude and longitude data were not available to the analyst due to confidentiality restrictions which precluded specification of a model that accounts for spatial autocorrelation more precisely. Incorporating clustering by postcode assumes non-zero correlation between women living within the same postcode area, but not for women living in different postcodes, regardless of their actual spatial distance. Women residing in neighbouring postcodes were assumed independent, even if they were spatially proximal.

\section{Prevalence of self-reported disease}

Relative risks (risk ratios, RRs) were modelled via Poisson regression with a $\log$ link function and robust error variance, which is known to produce consistent

\begin{tabular}{|c|c|c|c|c|}
\hline \multirow[b]{2}{*}{ Response to } & \multicolumn{3}{|l|}{ Cohort } & \multirow[b]{2}{*}{ Total } \\
\hline & Younger & Middle-aged & Older & \\
\hline Only survey 4 & $1865(18.5 \%)$ & & & 1865 (6.9\%) \\
\hline Only survey 5 & $920(9.1 \%)$ & $1112(10.0 \%)$ & 1748 (30.1\%) & $3780(14.0 \%)$ \\
\hline Only survey 6 & & 485 (4.4\%) & $243(4.2 \%)$ & 728 (2.7\%) \\
\hline Both surveys & $7280(72.3 \%)$ & $9526(85.6 \%)$ & $3812(65.7 \%)$ & $20618(76.4 \%)$ \\
\hline Total & $10065(100 \%)$ & $11123(100 \%)$ & $5803(100 \%)$ & $26991(100 \%)$ \\
\hline
\end{tabular}


and efficient estimates of relative risk with binary data. $^{21} 22$ The model chosen was a population-averaged model estimated by generalised estimating equations assuming an exchangeable correlation structure using the function xtgee in Stata 13.1 (StataCorp, College Station, Texas, USA). A linear association was assumed for the $\mathrm{NO}_{2}$ exposure and RR estimates are for an IQR increase. Proximities to major and minor roads were logtransformed (base 2) as the distribution was concentrated near zero and highly right-skewed; thus, estimated coefficients refer to a doubling in the exposure distance.

\section{Prevalence of self-reported symptoms}

ORs were estimated via a two-level mixed logistic regression with a random intercept that accounts for the dependence between repeated observations for each respondent. To partially account for spatial autocorrelation, an additional three-level mixed logistic regression with random intercepts for both respondent and postcode was used that accounts for the dependence between observations at both levels (see online supplementary section 4 for further details). Random intercepts were assumed to be normally distributed. Models were estimated by mean-variance adaptive Gauss-Hermite quadrature using the Stata 13.1 function melogit. Preliminary models were estimated with 10 quadrature points and the final model was estimated with 10,15 and 20 quadrature points to check the stability of the results.

\section{Models estimated}

We first estimated crude effect estimates and then second adjusted for confounders and known risk factors. Known risk factors for each outcome were included as a minimum: specifically, age cohort and smoking status were controlled in all models. ${ }^{23}$ Other confounders were identified by the 'change-in-estimate' rule of thumb; ${ }^{24} 25$ we required only a relatively small $5 \%$ change as effect estimates were expected to be small. Physical activity and BMI group were always included in models of diabetes and cardiovascular outcomes. BMI group was always included in the asthma model. Alcohol use was always included in models of hypertension and stroke. Comorbidities were not considered.

To assess the sensitivity of our results to the accuracy of address geocoding, we re-estimated the adjusted model on the subset of respondents with exact matches between respondent addresses at survey and the geocoded national address reference file. Finally, to assess residual confounding by variables excluded by this procedure, a further model containing all available covariates was estimated (here termed as a 'fully adjusted' model).

Model comparison was assisted by the quasi-likelihood under-the-independence-model information criterion $^{26} 27$ in the models of disease prevalence and Akaike's information criterion (AIC) in the models of symptom prevalence. Details of goodness-of-fit assessment are provided in online supplementary section 5 . Power analyses were conducted by simulation to determine the minimum detectable effect sizes given our model and sample size. CIs at the $99 \%$ level were used to reduce the risk of type 1 errors.

\section{RESULTS}

\section{Exposures}

Figure 1 shows distributions of annual mean $\mathrm{NO}_{2}$ levels and distance to roads at survey 5 of the younger cohort and surveys 6 of the middle-aged and older cohorts. A high level of spatial autocorrelation was observed in the $\mathrm{NO}_{2}$ data using the Moran's I statistic ( $\mathrm{I}=0.89, \mathrm{Z}=357.1$, $\mathrm{p}<0.001)$.

\section{Prevalence of self-reported disease}

Table 2 shows crude and adjusted relative risk estimates for the disease outcomes. Most adjusted RR estimates were close to unity for the $\mathrm{NO}_{2}$ exposure, and the $99 \%$ CIs included unity for all disease outcomes considered after adjusting for risk factors and confounders. Similarly, there was no evidence of association between any of the outcomes considered and residential proximity to major or minor roads. This was also the case when restricting the sample to those respondents with exact matches between address recorded at survey and the geocoding reference data. Adjusting for all available covariates did not suggest any residual confounding by the additional available variables and minimal change in precision of the estimated effects. Sensitivity analyses of the $5 \mathrm{~km}$ threshold for residential mobility suggested that the results were not affected by moving the threshold above or below $5 \mathrm{~km}$ (see online supplementary figures S1 and S2). Furthermore, no associations were observed with iron deficiency (as a negative control),
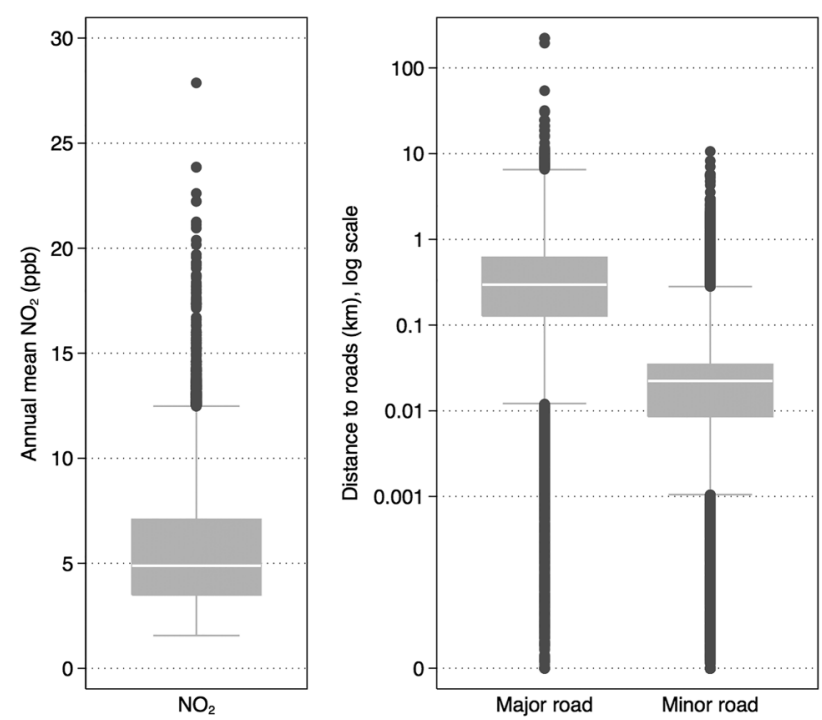

Figure 1 Box plots of annual mean $\mathrm{NO}_{2}$ levels and distance to roads at survey 5 of the younger cohort and surveys 6 of the middle-aged and older cohorts. 
Table 2 Relative risk of self-reported disease with an IQR increase in the 3-year mean $\mathrm{NO}_{2}$ concentration or a doubling in the distance to a major or minor road

\begin{tabular}{|c|c|c|c|c|c|c|c|c|}
\hline & \multicolumn{2}{|c|}{ Crude model } & \multicolumn{2}{|c|}{ Adjusted model* } & \multicolumn{2}{|c|}{$\begin{array}{l}\text { Fully adjusted } \\
\text { model } \dagger\end{array}$} & \multicolumn{2}{|c|}{$\begin{array}{l}\text { Exact geocoding } \\
\text { subsample* }\end{array}$} \\
\hline & $\bar{N}$ & RR (99\% Cl) & $\mathbf{N}$ & RR (99\% Cl) & $\overline{\mathbf{N}}$ & RR (99\% Cl) & $\overline{\mathbf{N}}$ & RR (99\% Cl) \\
\hline \multicolumn{9}{|l|}{ Diabetes } \\
\hline 3-year mean annual $\mathrm{NO}_{2}(3.7 \mathrm{ppb})$ & 14563 & 0.79 (0.70 to 0.89$)$ & 12443 & $1.04(0.91$ to 1.20$)$ & 12177 & 1.04 (0.90 to 1.20$)$ & 9738 & 1.00 (0.85 to 1.18$)$ \\
\hline Distance to major road (doubling) & 14563 & 1.04 (1.00 to 1.07$)$ & 12940 & 0.99 (0.95 to 1.04$)$ & 12177 & 0.99 (0.95 to 1.04$)$ & 10103 & 0.99 (0.93 to 1.05$)$ \\
\hline Distance to minor road (doubling) & 14563 & 1.11 (1.07 to 1.15$)$ & 12940 & 0.99 (0.95 to 1.04$)$ & 12177 & 0.98 (0.94 to 1.02$)$ & 10103 & 0.94 (0.87 to 1.02$)$ \\
\hline \multicolumn{9}{|l|}{ Heart disease } \\
\hline 3-year mean annual $\mathrm{NO}_{2}(3.7 \mathrm{ppb})$ & 14563 & 0.85 (0.77 to 0.93$)$ & 12452 & 0.94 (0.85 to 1.04$)$ & 12177 & 0.88 (0.76 to 1.01$)$ & 9739 & 0.90 (0.80 to 1.00$)$ \\
\hline Distance to major road (doubling) & 14563 & $1.03(1.00$ to 1.05$)$ & 12940 & 1.01 (0.97 to 1.05$)$ & 12177 & 1.01 (0.97 to 1.05$)$ & 10103 & 1.01 (0.96 to 1.06$)$ \\
\hline Distance to minor road (doubling) & 14563 & $1.11(1.08$ to 1.15$)$ & 12940 & 0.98 (0.95 to 1.02$)$ & 12177 & 0.98 (0.94 to 1.01$)$ & 10103 & 1.01 (0.93 to 1.09$)$ \\
\hline \multicolumn{9}{|l|}{ Hypertension } \\
\hline 3-year mean annual $\mathrm{NO}_{2}(3.7 \mathrm{ppb})$ & 14563 & $0.83(0.78$ to 0.87$)$ & 12395 & 0.97 (0.92 to 1.01$)$ & 12177 & 0.99 (0.94 to 1.05$)$ & 9687 & 0.96 (0.91 to 1.01$)$ \\
\hline Distance to major road (doubling) & 14563 & $1.03(1.02$ to 1.05$)$ & 12880 & 1.00 (0.98 to 1.02$)$ & 12177 & 1.00 (0.98 to 1.02$)$ & 10048 & 1.00 (0.98 to 1.02$)$ \\
\hline Distance to minor road (doubling) & 14563 & $1.12(1.10$ to 1.14$)$ & 12880 & 1.01 (0.99 to 1.02$)$ & 12177 & 1.00 (0.99 to 1.02$)$ & 10048 & 1.01 (0.98 to 1.04$)$ \\
\hline \multicolumn{9}{|l|}{ Stroke } \\
\hline 3-year mean annual $\mathrm{NO}_{2}(3.3 \mathrm{ppb})$ & 10402 & 0.99 (0.80 to 1.22$)$ & 8518 & 0.83 (0.58 to 1.19$)$ & 8384 & 0.74 (0.51 to 1.09$)$ & 6916 & 0.73 (0.49 to 1.09$)$ \\
\hline Distance to major road (doubling) & 10402 & 0.96 (0.89 to 1.05$)$ & 8964 & 1.01 (0.90 to 1.14$)$ & 8384 & $1.02(0.90$ to 1.16$)$ & 7252 & 1.06 (0.91 to 1.24$)$ \\
\hline Distance to minor road (doubling) & 10402 & 0.98 (0.89 to 1.08$)$ & 8964 & $0.98(0.88$ to 1.10$)$ & 8384 & 0.99 (0.88 to 1.11$)$ & 7252 & 1.13 (0.94 to 1.35$)$ \\
\hline \multicolumn{9}{|l|}{ Asthma } \\
\hline 3-year mean annual $\mathrm{NO}_{2}(3.7 \mathrm{ppb})$ & 14563 & 0.96 (0.89 to 1.05$)$ & 13660 & 0.99 (0.91 to 1.08$)$ & 12177 & 0.97 (0.86 to 1.10$)$ & 10658 & 0.95 (0.86 to 1.06$)$ \\
\hline Distance to major road (doubling) & 14563 & $1.00(0.97$ to 1.03$)$ & 13660 & 1.00 (0.98 to 1.03$)$ & 12177 & $1.00(0.97$ to 1.03$)$ & 10658 & 1.01 (0.97 to 1.05$)$ \\
\hline Distance to minor road (doubling) & 14563 & 1.00 (0.98 to 1.03$)$ & 13660 & $1.00(0.97$ to 1.03$)$ & 12177 & 1.01 (0.98 to 1.04$)$ & 10658 & 1.01 (0.95 to 1.07$)$ \\
\hline \multicolumn{9}{|l|}{ COPD } \\
\hline 3-year mean annual $\mathrm{NO}_{2}(3.7 \mathrm{ppb})$ & 14563 & $1.02(0.92$ to 1.13$)$ & 14480 & 0.96 (0.83 to 1.09$)$ & 12177 & $1.00(0.86$ to 1.17$)$ & 11294 & 0.92 (0.78 to 1.09$)$ \\
\hline Distance to major road (doubling) & 14563 & $1.01(0.97$ to 1.04$)$ & 14489 & 1.01 (0.97 to 1.04$)$ & 12177 & 1.01 (0.98 to 1.05$)$ & 11295 & 1.00 (0.95 to 1.06$)$ \\
\hline Distance to minor road (doubling) & 14563 & 0.99 (0.96 to 1.02$)$ & 14489 & 0.99 (0.95 to 1.02$)$ & 12177 & $1.00(0.95$ to 1.04$)$ & 11295 & 0.96 (0.89 to 1.04$)$ \\
\hline \multicolumn{9}{|l|}{ Iron deficiency—negative control } \\
\hline 3-year mean annual $\mathrm{NO}_{2}(3.7 \mathrm{ppb})$ & 14563 & 1.17 (1.09 to 1.26$)$ & 14563 & $1.04(0.96$ to 1.12$)$ & 12177 & 1.04 (0.93 to 1.16$)$ & 11355 & 1.02 (0.93 to 1.12$)$ \\
\hline Distance to major road (doubling) & 14563 & 0.95 (0.93 to 0.97$)$ & 14563 & 0.98 (0.96 to 1.00$)$ & 12177 & 0.99 (0.97 to 1.01$)$ & 11355 & 0.98 (0.94 to 1.02$)$ \\
\hline Distance to minor road (doubling) & 14563 & 0.93 (0.91 to 0.95$)$ & 14563 & 1.00 (0.98 to 1.03$)$ & 12177 & 1.01 (0.98 to 1.04$)$ & 11355 & 1.01 (0.95 to 1.07$)$ \\
\hline
\end{tabular}

Sample size (N) and RRs with $99 \%$ Cls in parentheses.

${ }^{*}$ Adjusted for known risk factors and identified confounders, specifically: diabetes models adjusted for cohort, BMI group, smoking status, physical activity, and additionally highest qualification and residential remoteness in the $\mathrm{NO}_{2}$ model; heart disease models adjusted for cohort, $\mathrm{BMI}$ group, smoking status, physical activity and additionally highest qualification in the $\mathrm{NO}_{2}$ model;

hypertension models adjusted for cohort, BMl group, smoking status, physical activity, alcohol use and additionally highest qualification in the $\mathrm{NO}_{2}$ models; stroke models adjusted for cohort,

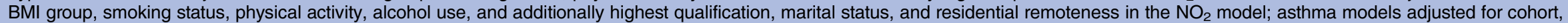

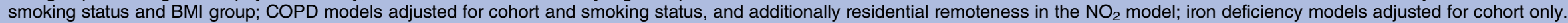

†Adjusted for all available covariates.

$\mathrm{BMI}$, body mass index; COPD, chronic obstructive pulmonary disease; RR, risk ratio. 
suggesting our results were not affected by unobserved confounding. Power simulations suggested that the models of stroke prevalence and most $\mathrm{NO}_{2}$ models may not have sufficient power to detect weak associations close to unity (see online supplementary tables S4 and S5).

\section{Prevalence of self-reported symptoms}

Table 3 shows crude and adjusted ORs for the symptom outcomes. Again there was no evidence of association between annual mean $\mathrm{NO}_{2}$ levels, or residential proximity to major or minor roads, and any of the symptoms considered after adjusting for risk factors and confounders. This was also the case when adjusting for all available covariates, when the analytical sample was restricted to those respondents with exact matches between address recorded at survey and the geocoding reference data, and when three-level models were estimated which account for clustering by postcode. The findings were stable when using 10,15 or 20 integration points for the adaptive Gauss-Hermite quadrature.

\section{Spatial autocorrelation}

The estimated within-postcode correlations in the disease prevalence models were negligible $(<0.012$ in absolute value in all cases), suggesting little benefit in estimating this additional parameter. Within-postcode correlations were also of negligible magnitude in the symptom prevalence models $(\leq 0.01$ in absolute value in all cases), and there was negligible difference in AIC when comparing the three-level models with their corresponding nested two-level models, suggesting no clustering by postcode.

\section{DISCUSSION}

This is the first Australian national-scale air pollution study focusing on the effects of long-term ambient air pollution exposure on chronic morbidity in women. We linked individual-level data on self-reported symptoms and diseases (and confounding variables) to residential exposure estimates from a validated land-use regression model and accounted for spatial clustering of respondents. We found no evidence of associations between self-reported diabetes, heart disease, hypertension, stroke, asthma, COPD or self-reported symptoms of allergies, breathing difficulties, chest pain or palpitations and ambient $\mathrm{NO}_{2}$ air pollution exposure or residential proximity to roads after adjusting for known risk factors and confounders.

\section{Comparison with other studies \\ Diabetes mellitus type 2}

Although experimental evidence suggests a role for air pollution in the aetiology of diabetes, epidemiological evidence linking air pollution and diabetes prevalence is limited and mixed..$^{28}$ Our results are consistent with one of two recent systematic reviews and meta-analyses of cross-sectional studies: Janghorbani $e t a l^{29}$ found no association while Balti et $a t^{4}$ suggested exposure to ambient $\mathrm{NO}_{2}$ air pollution may be associated with a modest increase in diabetes prevalence. Both reviews relied on a different set of two out of three available cross-sectional studies, of which two found no association ${ }^{11}{ }^{30}$ and the third observed a positive association. ${ }^{28}$ We were unable to exclude participants with type 1 diabetes in the middle-aged and older cohorts, which may have diluted our observed effects. However, the overwhelming majority of cases in these age groups in our data set are type 2 diabetes.

\section{Respiratory and allergic outcomes}

It is well known that air pollution exacerbates symptoms in individuals already suffering from asthma and allergic conditions; ${ }^{9} 103132$ however, the role that air pollution plays in the development of asthma and allergies is less clear. ${ }^{9}{ }^{10}$ Recent systematic reviews and meta-analyses suggest an association between increases in ambient $\mathrm{NO}_{2}$ air pollution and asthma incidence, ${ }^{5}$ but not community-level prevalence. ${ }^{33}$ Few studies of withincommunity prevalence have looked at adult asthma, ${ }^{32}$ with some of those conducted to date reporting positive associations $^{34} 35$ and others, consistent with our study, reporting no association. ${ }^{36} 37$ Our findings are also supported by a recent Tasmanian study that found no associations between adult asthma prevalence and traffic-related pollution. ${ }^{38}$ In the case of allergic disease, our results are consistent with those of Pujades-Rodríguez et $a l^{37}$ but not with results of Cesaroni et $a \vec{l}^{36}$ who observed an association between rhinitis prevalence and various traffic-related indicators or Lindgren et al, ${ }^{35}$ who observed associations between allergic rhinitis (hay fever), proximity to traffic and exposure to nitrogen oxides $\left(\mathrm{NO}_{\mathrm{X}}\right)$. A limitation of our analysis was the lack of information with which to separate allergic from non-allergic asthma, ${ }^{10}$ and the broad categorisation of allergies, hay fever and sinusitis as one outcome when the underlying conditions may have varying subtypes and aetiologies.

The evidence for long-term air pollution effects on COPD prevalence is also not conclusive, despite the existence of biologically plausible mechanisms and wellestablished evidence that air pollution affects lung function and exacerbates pre-existing COPD. ${ }^{39} 40$ Our results are consistent with two recent meta-analyses: associations between $\mathrm{NO}_{2}$ exposure and chronic bronchitis symptoms were not observed in the European Study of Cohorts for Air Pollution Effects ${ }^{41}$ or in a systematic review of the effect of outdoor PM air pollution on COPD prevalence. ${ }^{42}$ Moreover, the majority of crosssectional studies reviewed by Schikowski et $a \vec{l}^{9}$ observed no association. In contrast, $\mathrm{NO}_{2}$ and $\mathrm{PM}$ exposure were both associated with a higher risk of COPD in a study of German women, ${ }^{43}$ while proximity to busy roads and long-term $\mathrm{NO}_{\mathrm{x}}$ exposure were associated with a higher risk of self-reported COPD and chronic bronchitis 
Table 3 ORs of self-reported symptoms with an IQR increase in the annual mean $\mathrm{NO}_{2}$ concentration or a doubling in the distance to a major or minor road

\section{Crude model}

$\mathbf{N}$ OR $(99 \%$

\section{Adjusted model*} N OR $(99 \% \mathrm{Cl})$

Fully adjusted

modelt

Allergies

Annual mean $\mathrm{NO}_{2}$ (3.7 ppb)

Distance to major

road (doubling)

Distance to minor road (doubling)

Breathing difficulty

Annual mean $\mathrm{NO}_{2}$ (3.4 ppb)

Distance to major road (doubling)

Distance to minor road (doubling)

Chest pain

Annual mean $\mathrm{NO}_{2}$ (3.2 ppb)

Distance to major

road (doubling)

Distance to minor road (doubling)

Palpitations

Annual mean $\mathrm{NO}_{2}$

(3.7 ppb)

Distance to major

road (doubling)

Distance to minor road (doubling)

357971.00 (0.97 to 1.

357

35457

3545

35457
$357971.02(0.92$ to 1.13$) \quad 35496 \quad 0.87(0.76$ to 1.01$) \quad 30410 \quad 0.87(0.76$ to 1.01$)$

$281940.96(0.88$ to 1.05$) \quad 23315 \quad 0.96(0.87$ to 1.06$) \quad 20823 \quad 1.00(0.87$ to 1.15$) \quad 16279 \quad 0.90(0.80$ to 1.01$) \quad 17868 \quad 0.94(0.84$ to 1.06$)$ $281940.98(0.95$ to 1.02$) \quad 233151.00(0.96$ to 1.04$) \quad 20823 \quad 1.00(0.96$ to 1.04$) \quad 16279 \quad 0.94(0.98$ to 1.10$) \quad 17868 \quad 1.02(0.97$ to 1.07$)$ $281940.98(0.95$ to 1.01$) \quad 233151.00(0.96$ to 1.03$) \quad 20823 \quad 0.99(0.95$ to 1.02$) \quad 16279 \quad 0.97(0.90$ to 1.05$) \quad 17868 \quad 0.99(0.94$ to 1.04$)$

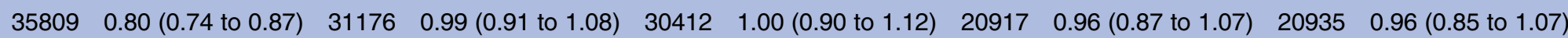
$358091.04(1.02$ to 1.06$) \quad 330621.00(0.98$ to 1.03$) \quad 30412 \quad 1.01(0.98$ to 1.03$) \quad 22167 \quad 1.01(0.97$ to 1.04$) \quad 21669 \quad 1.02(0.98$ to 1.05$)$ $358091.08(1.05$ to 1.10$) \quad 330621.00(0.97$ to 1.02$) \quad 30412 \quad 0.99(0.97$ to 1.02$) \quad 22167 \quad 1.00(0.96$ to 1.05$) \quad 21669 \quad 0.98(0.94$ to 1.02$)$

Sample size including repeated observations $(\mathrm{N})$ and ORs with $99 \%$ Cls in parentheses; models are two-level models unless specified otherwise.

*Adjusted for known risk factors and identified confounders, specifically: models of allergies adjusted for cohort and smoking status and additionally residential remoteness in the $\mathrm{NO}_{2}$ model;

models of breathing difficulty symptoms adjusted for cohort and smoking status, and additionally highest qualification in the $\mathrm{NO}_{2}$ model; models of chest pain symptoms adjusted for cohort, BMI

group, smoking status and physical activity; models of palpitations symptoms adjusted for cohort, $\mathrm{BMI}$ group, smoking status, physical activity and additionally highest qualification in the $\mathrm{NO}_{2}$

model.

†Adjusted for all available covariates.

BMI, body mass index. 
symptoms in a Swedish study. ${ }^{34}$ Inconsistencies in findings between these cross-sectional studies are thought to be due to differences in exposure measurement, misclassification, migration and heterogeneous assessment of confounders. ${ }^{39}$

\section{Cardiovascular outcomes}

The adverse effects of PM air pollution on cardiovascular health are established ${ }^{44}$ and the consensus of published evidence suggests a causal association between air pollution and cardiovascular disease even at concentrations below existing air quality standards. ${ }^{45} 46$ While long-term effects on mortality due to PM have been well documented, the evidence for effects on cardiovascular morbidity have been less consistent. ${ }^{8}{ }^{47}$ In contrast to our findings for heart disease, positive cross-sectional associations have been observed with long-term exposure to $\mathrm{PM}^{48}$ and high traffic exposure. ${ }^{49}$ Cross-sectional associations with $\mathrm{NO}_{2}$ pollution are less understood, with some studies reporting positive associations ${ }^{50}$ and others no association. ${ }^{51}$ Experimental studies suggest low cardiovascular toxicity of $\mathrm{NO}_{2}$ at ambient concentrations $^{52} 53$ and inconsistencies in findings between observational studies are thought to be due to exposure to co-pollutants or the combined effects of pollutant mixtures. $^{44}$

Although traffic-related pollution has been associated with increases in blood pressure, ${ }^{54}{ }^{55}$ few studies of longterm exposure to ambient air pollution and hypertension prevalence have been conducted. The effect of air pollution on blood pressure is considered a potential mechanism that may explain the established association between ambient air pollution and cardiovascular disease ${ }^{54}{ }^{55}$ Our results are consistent with several previous studies that observed no association between hypertension prevalence and exposure to $\mathrm{NO}_{2}$ or $\mathrm{PM}$ pollution ${ }^{55}{ }^{56}$ but are inconsistent with the positive association with PM exposure observed by Johnson and Parker, ${ }^{48}$ and the inverse association with exposure to $\mathrm{NO}_{\mathrm{x}}$ observed by Sørensen $e t$ al. ${ }^{57}$ The differences in findings between studies are thought to be due to differential diagnostic criteria or misclassification of hypertension cases which are often undiagnosed ${ }^{54} 55$; however, the latter is unlikely to be relevant in Australia where blood pressure measurement is frequent and widespread.

Long-term air pollution exposure has been associated with stroke hospitalisations and mortality, ${ }^{58}$ and there is growing evidence that it has an impact on the development of carotid arteriosclerosis which is a precursor of stroke. ${ }^{59}$ However, limited evidence has been presented for an association with stroke prevalence. Consistent with our finding, Dong $e t a l^{14}$ and Forbes $e t a l^{51}$ observed no association with ambient $\mathrm{NO}_{2}$ air pollution among Chinese or English women, respectively, whereas associations with PM pollution were observed by Dong et al, but not by Forbes et al. Brauer ${ }^{59}$ suggests a limitation in studies that fail to separate ischaemic from haemorrhagic stroke, as air pollution is considered to variably affect the underlying pathophysiological mechanisms.

\section{Limitations}

Our results should be considered in the context of the following limitations. Although the ALSWH study and its self-report data have been extensively documented and validated, the study was not conceived as an air pollution study. Moreover, rural areas which typically have low air pollution levels are considerably over-represented in the ALSWH, and the use of subject-specific sampling weights was precluded by our choice of methodology. While our $\mathrm{NO}_{2}$ data have been validated, ${ }^{19}$ we were not able to assess the validity of our road proximity variables.

Several avenues of exposure misclassification may be present. First, as this is a cross-sectional study of disease prevalence rather than incidence, there is uncertainty in the degree to which exposure preceded the outcomes observed. However, high correlation was observed between annual average pollution levels in successive years during the study period. Second, we defined an arbitrary threshold for residential mobility between surveys of $5 \mathrm{~km}$. Even with the analysis limited to movement below the threshold, exposures may be misclassified for some respondents. However, sensitivity analyses revealed no appreciable change in our estimates with thresholds of $1-10 \mathrm{~km}$. Lastly, we did not account for occupational and transport-related exposures, nor indoor sources of $\mathrm{NO}_{2}$ such as unflued gas stoves and heaters. We believe that each of these avenues of exposure misclassification could be non-differential and that the likely consequences are effects that are biased towards the null. A further source of potential bias towards the null may be the uncertainty inherent in exposure estimates from our land-use regression model. ${ }^{60}$ In addition, prevalence studies may be affected by exposure-induced migration patterns, with susceptible individuals moving to lower exposure areas. ${ }^{3361}$

As the study was based on self-reported assessment of health status and health-related variables, there may be misclassification in the outcome and covariate data. Undiagnosed and untreated cases may not have been reported, and there may have been misreporting of diagnoses or sensitive health-related characteristics such as weight, level of physical activity and alcohol use. However, validation studies of ALSWH self-report data suggest substantial agreement with hospital records for diabetes and to a reasonable degree, for heart disease and stroke. ${ }^{62}$ The validity of self-reported height, weight and physical activity have also been assessed and confirmed by previous studies. ${ }^{63}$ Although we were able to adjust for a wide array of potential confounders, residual confounding may nonetheless exist due to the coarse resolution of some covariates such as smoking. In addition, we were not able to assess the effects of traffic noise and therefore, cannot rule out residual confounding by exposure to noise. 
As spatial autocorrelation was observed in the $\mathrm{NO}_{2}$ exposure, we accounted for clustering by postcode. While this assumption allows for non-zero correlation between women living within the same postcode, it does not allow for correlation between spatially proximal women living in differing postcodes. An inability to completely account for spatial autocorrelation may be a source of bias in our study. However, there appeared to be minimal clustering by postcode based on the magnitude of the estimated within-postcode correlation.

Although we concentrated on exposure to ambient $\mathrm{NO}_{2}$ as a marker for combustion-derived air pollution, individuals are exposed to a mixture of pollutants. However, we also analysed residential proximity to roads as a marker for the diverse mix of traffic-related ambient air pollution and our conclusions remain unchanged. Finally, as we studied the relationship between long-term exposure to ambient air pollution and chronic morbidity in women, our results cannot be extrapolated to the short-term effects of ambient air pollution or generalised to effects in men.

\section{CONCLUSION}

We observed no evidence of association between estimated long-term ambient $\mathrm{NO}_{2}$ exposure and selfreported diseases (diabetes, heart disease, hypertension, stroke, asthma, COPD) and symptoms (allergies, breathing difficulties, chest pain, palpitations) in a cohort of 26991 Australian women born in 1921-1926, 1946-1951 and 1973-1978. The observed results may be due to an inherently low signal-to-noise ratio with uncertainty in both outcome and exposure measurement, and therefore the potential for misclassification which may have biased the results towards the null; lack of power to detect modest $\mathrm{NO}_{2}$ effect sizes for some health conditions; or may reflect an absence of effects at the relatively low annual average $\mathrm{NO}_{2}$ levels observed in Australia. Nonetheless, several of our findings are consistent with those observed in other work. Our study adds to the limited evidence base on the long-term effects of ambient $\mathrm{NO}_{2}$ air pollution and traffic exposure on chronic cardiorespiratory, metabolic and allergic conditions in women.

\section{Twitter Follow Adrian Barnett at @aidybarnett}

Acknowledgements The research on which this paper is based was conducted as part of the Australian Longitudinal Study on Women's Health by the University of Newcastle and the University of Queensland. The authors are grateful to the women who provided their time and personal data in the surveys, and the Australian Government Department of Health for funding the ALSWH. They thank the ALSWH team for their assistance with the data.

Contributors NL performed the statistical analysis and prepared the manuscript. LDK coordinated the study and performed the exposure assessment. AJD and AGB guided the statistical analyses. LDK and AGB conceived the idea and initiated the study. All authors were involved in the study design, critically reviewed drafts, and have read and approved the final manuscript.

Funding LDK was supported by an NHMRC Early Career (Australian Public Health) Fellowship (APP1036620). The Australian Longitudinal Study on
Women's Health is funded by the Australian Government Department of Health.

Competing interests None declared.

Ethics approval The ALSWH is approved by the human research ethics committees of the University of Queensland and the University of Newcastle.

Provenance and peer review Not commissioned; externally peer reviewed.

Data sharing statement $\mathrm{ALSWH}$ and $\mathrm{NO}_{2}$ exposure data are available (see http://www.alswh.org.au and Knibbs et $\mathrm{al}^{19}$ ).

Open Access This is an Open Access article distributed in accordance with the Creative Commons Attribution Non Commercial (CC BY-NC 4.0) license, which permits others to distribute, remix, adapt, build upon this work noncommercially, and license their derivative works on different terms, provided the original work is properly cited and the use is non-commercial. See: http:// creativecommons.org/licenses/by-nc/4.0/

\section{REFERENCES}

1. Lim SS, Vos T, Flaxman AD, et al. A comparative risk assessment of burden of disease and injury attributable to 67 risk factors and risk factor clusters in 21 regions, 1990-2010: a systematic analysis for the Global Burden of Disease Study 2010. Lancet 2012;380:2224-60.

2. Cohen AJ, Anderson HR, Ostro B, et al. The global burden of disease due to outdoor air pollution. $J$ Toxicol Environ Health $A$ 2005;68:1301-7.

3. Hansen A, Bi P, Nitschke M. Air pollution and cardiorespiratory health in Australia: the impact of climate change. Environ Health 2009:9:17.

4. Balti EV, Echouffo-Tcheugui JB, Yako YY, et al. Air pollution and risk of type 2 diabetes mellitus: a systematic review and meta-analysis. Diabetes Res Clin Pract 2014;106:161-72.

5. Anderson HR, Favarato G, Atkinson RW. Long-term exposure to air pollution and the incidence of asthma: meta-analysis of cohort studies. Air Qual Atmos Health 2011;6:47-56.

6. Mustafic $\mathrm{H}$, Jabre $\mathrm{P}$, Caussin $\mathrm{C}$, et al. Main air pollutants and myocardial infarction: a systematic review and meta-analysis. JAMA 2012;307:713-21

7. Yang W-S, Wang X, Deng Q, et al. An evidence-based appraisal of global association between air pollution and risk of stroke. Int $J$ Cardiol 2014;175:307-13.

8. Brook RDR, Rajagopalan SS, Pope CAC, et al. Particulate matter air pollution and cardiovascular disease: an update to the scientific statement from the American Heart Association. Circulation 2010;121:2331-78.

9. Gowers AM, Cullinan P, Ayres JG, et al. Does outdoor air pollution induce new cases of asthma? Biological plausibility and evidence; a review. Respirology 2012;17:887-98.

10. Carlsten C, Melén E. Air pollution, genetics, and allergy: an update. Curr Opin Allergy Clin Immunol 2012;12:455-60.

11. Brook RD, Jerrett M, Brook JR, et al. The relationship between diabetes mellitus and traffic-related air pollution. $J$ Occup Environ Med 2008;50:32-8.

12. Chen LH, Knutsen SF, Shavlik D, et al. The association between fatal coronary heart disease and ambient particulate air pollution: are females at greater risk? Environ Health Perspect 2005;113: 1723-9.

13. Künzli N, Jerrett M, Mack WJ, et al. Ambient air pollution and atherosclerosis in Los Angeles. Environ Health Perspect 2005;113:201-6.

14. Dong G-H, Qian ZM, Wang J, et al. Associations between ambient air pollution and prevalence of stroke and cardiovascular diseases in 33 Chinese communities. Atmospheric Environ 2013;77:968-73.

15. Lee C, Dobson AJ, Brown WJ, et al. Cohort profile: the Australian Longitudinal Study on Women's Health. Int J Epidemiol 2005;34:987-91.

16. Lipsitch M, Tchetgen Tchetgen E, Cohen T. Negative controls: a tool for detecting confounding and bias in observational studies. Epidemiology 2010;21:383-8.

17. Lindeboom M, van Doorslaer E. Cut-point shift and index shift in self-reported health. $J$ Health Econ 2004;23:1083-99.

18. Groot W. Adaptation and scale of reference bias in self-assessments of quality of life. J Health Econ 2000;19:403-20.

19. Knibbs LD, Hewson MG, Bechle MJ, et al. A national satellite-based land-use regression model for air pollution exposure assessment in Australia. Environ Res 2014;135:204-11. 
20. Jerrett $M$, Arain A, Kanaroglou $P$, et al. A review and evaluation of intraurban air pollution exposure models. J Expo Anal Environ Epidemiol 2005;15:185-204.

21. Zou G. A modified Poisson regression approach to prospective studies with binary data. Am J Epidemiol 2004;159:702-6.

22. Yelland LN, Salter AB, Ryan P. Performance of the modified Poisson regression approach for estimating relative risks from clustered prospective data. Am J Epidemiol 2011;174:984-92.

23. Australian Institute of Health and Welfare. Risk factors contributing to chronic disease. 2012 (cited 27 April 2015); AlHW cat. no. PHE157. Canberra: AlHW. http://www.aihw.gov.au/publication-detail/ ?id=10737421466

24. Rothman KJ, Greenland S, Lash TL. Modern epidemiology. Philadelphia: Lippincott Williams \& Wilkins, 2008. http://www.lww. com/Product/9781451190052

25. Lee $\mathrm{PH}$. Is a cutoff of $10 \%$ appropriate for the change-in-estimate criterion of confounder identification? J Epidemiol 2014;24:161-7.

26. Pan W. Akaike's information criterion in generalized estimating equations. Biometrics 2001;57:120-5.

27. Cui J. QIC program and model selection in GEE analyses. Stata J 2007;7:209-20.

28. Eze IC, Schaffner E, Fischer E, et al. Long-term air pollution exposure and diabetes in a population-based Swiss cohort. Environ Int 2014;70:95-105.

29. Janghorbani M, Momeni F, Mansourian M. Systematic review and metaanalysis of air pollution exposure and risk of diabetes. Eur $\mathrm{J}$ Epidemiol 2014;29:231-42.

30. Dijkema MBA, Mallant SF, Gehring U, et al. Long-term exposure to traffic-related air pollution and type 2 diabetes prevalence in a cross-sectional screening-study in the Netherlands. Environ Health 2011;10:76.

31. Kim K-H, Jahan SA, Kabir E. A review on human health perspective of air pollution with respect to allergies and asthma. Environ Int 2013;59:41-52.

32. Guarnieri M, Balmes JR. Outdoor air pollution and asthma. Lancet 2014;383:1581-92.

33. Anderson HR, Favarato G, Atkinson RW. Long-term exposure to outdoor air pollution and the prevalence of asthma: meta-analysis of multi-community prevalence studies. Air Qual Atmos Health 2011;6:57-68.

34. Lindgren A, Stroh E, Montnémery $P$, et al. Traffic-related air pollution associated with prevalence of asthma and COPD/chronic bronchitis. A cross-sectional study in Southern Sweden. Int J Health Geogr 2009;8:2-2.

35. Lindgren A, Stroh E, Nihlén $U$, et al. Traffic exposure associated with allergic asthma and allergic rhinitis in adults. A cross-sectional study in southern Sweden. Int J Health Geogr 2009;8:25.

36. Cesaroni G, Badaloni C, Porta D, et al. Comparison between various indices of exposure to traffic-related air pollution and their impact on respiratory health in adults. Occup Environ Med 2008;65: 683-90.

37. Pujades-Rodríguez M, Lewis S, Mckeever T, et al. Effect of living close to a main road on asthma, allergy, lung function and chronic obstructive pulmonary disease. Occup Environ Med 2009;66:679-84.

38. Bui DS, Burgess JA, Matheson MC, et al. Ambient wood smoke, traffic pollution and adult asthma prevalence and severity. Respirology 2013;18:1101-7.

39. Schikowski T, Mills IC, Anderson HR, et al. Ambient air pollution: a cause of COPD? Eur Respir J 2014;43:250-63.

40. Götschi T, Heinrich J, Sunyer J, et al. Long-term effects of ambient air pollution on lung function: a review. Epidemiology 2008;19:690-701.

41. Cai Y, Schikowski T, Adam M, et al. Cross-sectional associations between air pollution and chronic bronchitis: an ESCAPE meta-analysis across five cohorts. Thorax 2014;69:1005-14.

42. Song $Q$, Christiani DC, Wang XR, et al The global contribution of outdoor air pollution to the incidence, prevalence, mortality and hospital admission for chronic obstructive pulmonary disease: a systematic review and meta-analysis. Int $J$ Environ Res Public Health 2014;11:11822-32.

43. Schikowski T, Sugiri D, Ranft U, et al. Long-term air pollution exposure and living close to busy roads are associated with COPD in women. Respir Res 2005;6:152.

44. Shah AS, Langrish JP Nair $\mathrm{H}$, et al. Global association of air pollution and heart failure: a systematic review and meta-analysis. Lancet 2013;382:1039-48.

45. Simkhovich BZ, Kleinman MT, Kloner RA. Air pollution and cardiovascular injury epidemiology, toxicology, and mechanisms. J Am Coll Cardiol 2008;52:719-26.

46. Mills NL, Donaldson K, Hadoke PW, et al. Adverse cardiovascular effects of air pollution. Nat Clin Pract Cardiovasc Med 2009;6:36-44.

47. Bhaskaran $\mathrm{K}$, Hajat S, Haines A, et al. The effects of air pollution on the incidence of myocardial infarction. Heart 2009;95:1746-59.

48. Johnson D, Parker JD. Air pollution exposure and self-reported cardiovascular disease. Environ Res 2009;109:582-9.

49. Hoffmann B, Moebus S, Stang A, et al. Residence close to high traffic and prevalence of coronary heart disease. Eur Heart $J$ 2006;27:2696-702.

50. Beckerman BS, Jerrett M, Finkelstein M, et al. The association between chronic exposure to traffic-related air pollution and ischemic heart disease. J Toxicol Environ Health A 2012;75:402-11.

51. Forbes LJL, Patel MD, Rudnicka AR, et al. Chronic exposure to outdoor air pollution and diagnosed cardiovascular disease: meta-analysis of three large cross-sectional surveys. Environ Health 2009;8:30.

52. Langrish JP, Lundbäck M, Barath $\mathrm{S}$, et al. Exposure to nitrogen dioxide is not associated with vascular dysfunction in man. Inhal Toxicol 2010;22:192-8.

53. Mills NL, Miller MR, Lucking AJ, et al. Combustion-derived nanoparticulate induces the adverse vascular effects of diesel exhaust inhalation. Eur Heart $J$ 2011;32:2660-71.

54. Chan SH, Van Hee VC, Bergen S, et al. Long-term air pollution exposure and blood pressure in the Sister Study. Environ Health Perspect 2015;123:951-8.

55. Foraster M, Basagaña X, Aguilera I, et al. Association of long-term exposure to traffic-related air pollution with blood pressure and hypertension in an adult population-based cohort in Spain (the REGICOR study). Environ Health Perspect 2014;122:404-11.

56. Dong G-H, Qian ZM, Xaverius PK, et al. Association between long-term air pollution and increased blood pressure and hypertension in China. Hypertension 2013;61:578-84.

57. Sørensen M, Hoffmann B, Hvidberg M, et al. Long-term exposure to traffic-related air pollution associated with blood pressure and self-reported hypertension in a Danish cohort. Environ Health Perspect 2012;120:418-24.

58. Ljungman PL, Mittleman MA. Ambient air pollution and stroke. Stroke 2014;45:3734-41.

59. Brauer M. Air pollution, stroke, and anxiety. BMJ 2015;350:h1510-0.

60. Basagaña X, Aguilera I, Rivera M, et al. Measurement error in epidemiologic studies of air pollution based on land-use regression models. Am J Epidemiol 2013;178:1342-6.

61. Jacquemin B, Schikowski T, Carsin AE, et al. The role of air pollution in adult-onset asthma: a review of the current evidence. Semin Respir Crit Care Med 2012;33:606-19.

62. Navin Cristina TJ, Stewart Williams JA, Parkinson L, et al. Identification of diabetes, heart disease, hypertension and stroke in mid- and older-aged women: comparing self-report and administrative hospital data records. Geriatr Gerontol Int 2015.

63. Brown WJ, Burton NW, Marshall AL, et al. Reliability and validity of a modified self-administered version of the Active Australia physical activity survey in a sample of mid-age women. Aust $N Z J$ Public Health 2008;32:535-41.

64. Burton NW, Brown W, Dobson A. Accuracy of body mass index estimated from self-reported height and weight in mid-aged Australian women. Aust N Z J Public Health 2010;34:620-3. 